\title{
Musculatura da asa da arara canindé (Ara ararauna, Linnaeus, 1758): conhecimento básico aplicado à clínica de animais silvestres
}

\author{
Kamal Achôa Filho ${ }^{1 *}$ \\ Rafael Magdanelo Leandro ${ }^{1}$ \\ Marcio Nogueira Rodrigues ${ }^{2}$ \\ Erika Toledo da Fonseca ${ }^{2}$ \\ Vanessa Bertagia Pasqualetti ${ }^{1}$ \\ Maria Angelica Miglino ${ }^{2}$ \\ ${ }^{1}$ Universidade do Grande ABC/Anhanguera \\ Avenida Industrial, 3330, CEP 09080-501, Santo André - SP, Brasil \\ ${ }^{2}$ Universidade de São Paulo \\ Faculdade de Medicina Veterinária e Zootecnia, Departamento de Cirurgia \\ Avenida Prof. Dr. Orlando Marques de Paiva 87, CEP 05508-270, São Paulo - SP, Brasil \\ * Autor para correspondência \\ kafilho@gmail.com
}

Submetido em 24/07/2013

Aceito para publicação em 08/01/2014

\section{Resumo}

Este trabalho teve o objetivo de descrever a musculatura das asas da arara canindé (Ara ararauna), visando a contribuir para aumentar o conhecimento acerca de sua anatomia e auxiliar a prática clínica com essa espécie. Foram utilizadas cinco araras provenientes do Centro de Triagem de Animais Silvestres da Paraíba (Cetas-PB), sendo a musculatura identificada mediante dissecação direta. Os músculos flexores, assim como os extensores, mostraram-se bem definidos, tinham bom calibre e bom desenvolvimento, contribuindo, assim, para uma minuciosa descrição anatômica e para a definição de sua origem, inserção e funcionalidade nas asas das araras.

Palavras-chave: Arara canindé; Asa; Dissecação; Musculatura

\section{Abstract}

Wing muscles in blue-and-yellow Macaw (Ara ararauna, Linnaeus, 1758): basic knowledge applied to the clinic of wild animals. This paper aimed to describe the wing muscles in blue-and-yellow Macaw (Ara ararauna), in order to contribute to increase knowledge on its anatomy and help the clinical practice with this species. Five macaws from the Screening Center for Wild Animals in Paraíba (CETAS-PB) were used, and the muscles were identified by direct dissection. Flexor muscles, as well as extensor muscles, were well defined, had a good caliber and development, thus contributing to a detailed anatomical description and to a definition of their origin, insertion, and functionality in the wings of macaws.

Key words: Blue-and-yellow Macaw; Dissection; Muscles; Wing 


\section{Introdução}

A ordem Psitaciforme inclui as aves conhecidas como "aves do bico redondo", sendo divididas em três famílias: Loridae, Cacatuidae e Psitacidae. São aves muito populares, de fácil domesticação, e por isso são comumente mantidas em cativeiro como animais de estimação (SICK, 1997).

Sick (1997) afirma ainda que das 332 espécies e 78 gêneros conhecidos de Psitacídeos, 148 espécies são encontradas no Novo Mundo, 100 espécies ocorrem na América do Sul e 80 espécies são encontradas no Brasil, fazendo com que nosso país seja considerado o mais rico no mundo em espécies de psitacídeos. Do gênero Ara, são incluídas quatro espécies: A ararauna, A. chloropterus, A. macao e A. severus.

Como na grande maioria das aves, as Araras têm como seu principal meio de locomoção o voo (McLELLAND, 1990), sendo capazes de sincronizar a extensão das articulações do cotovelo e punho da asa, usando mecanismos de coordenação automatizada que envolve adaptação esquelética e muscular. No entanto, a força e o impulso gerado durante o ciclo do bater das asas e a complexa cinemática da asa durante o movimento exigem um mecanismo de controle ativo neuromuscular e adaptações especializadas dos músculos do voo inervados pelo plexo braquial (STURKIE, 2000).

Para Sick (1997), as habilidades dos psitacídeos são comumente exploradas devido a sua fácil domesticação. É possível encontrar Araras andando em minibicicletas ou rosqueando parafusos, por exemplo. Estas atividades expõem os animais a grandes riscos inclusive a graves lesões em suas asas, o que pode ocasionar a perda da habilidade de voo.

Tendo suas asas como principal membro de locomoção, as aves dependem de uma musculatura estruturada similar aos músculos estriados da maioria dos animais, com um grande número de longas fibras ou células alinhadas paralelamente (STURKIE, 2000).

Levando em conta a importância do conhecimento anatômico para futuros estudos clínicos direcionados a medicina veterinária de animais silvestres, o objetivo deste trabalho foi descrever toda a musculatura da asa de Araras Canindé de forma a contribuir com o conhecimento morfológico desta espécie.

\section{Material e Métodos}

Foram utilizadas cinco Araras Canindé (Ara ararauna, Linnaeus, 1758) previamente fixadas com solução aquosa de formaldeído a 4\%, doadas ao Setor de Anatomia dos Animais Domésticos e Silvestres da Faculdade de Medicina Veterinária e ZootecniaUniversidade de São Paulo, pelo CETAS-PB (Centro de Triagem de Animais Silvestres) O projeto foi aprovado pela Comissão de Ética no Uso de Animais da FMVZUSP sob o número 2619/2012.

Com o auxílio de tesoura e lâminas de bisturi (números 11, 15 e 20), procedeu-se a dissecação para identificação dos músculos componentes da asa. A pele e a tela subcutânea foram rebatidas mediante incisões dorsais e ventrais, possibilitando a visualização dos músculos. Após a limpeza de aponeuroses e fáscias presentes, foi realizada a identificação dos componentes musculares, assim como a origem e inserção de cada músculo. Em seguida as peças dissecadas foram fotografadas e os resultados compilados em pranchas e esquemas ilustrativos. A descrição dos componentes anatômicos foi realizada conforme o preconizado por Baumel et al. (1993).

\section{Resultados}

Para facilitar o entendimento dos resultados, optouse por dividi-los em tabelas, de acordo com a região anatômica descrita.

A Tabela 1 apresenta os músculos da face medial do braço (representados na Figura 1), suas respectivas funções, origens e inserções.

A Tabela 2 apresenta os músculos da face medial do antebraço (representados na Figura 2), suas respectivas funções, origens e inserções. 
TABELA 1: Músculos da face medial do braço das Araras-Canindé.

\begin{tabular}{lcccc}
\hline \multicolumn{1}{c|}{ Músculo } & Funções & Origem & Inserção \\
Peitoral torácico & $\begin{array}{c}\text { Tração cranial da asa, movimento de descida e } \\
\text { posicionamento ao planar }\end{array}$ & Esterno & Crista deltoide do úmero \\
\hline Peitoral propatagial & Tensionar o antebraço & Úmero & Epicôndilo lateral do úmero \\
\hline $\begin{array}{l}\text { Escapulotríceps } \\
\text { braquial }\end{array}$ & $\begin{array}{r}\text { Flexionar o ombro e estender a articulaçao do } \\
\text { cotovelo }\end{array}$ & Colo da Escápula & Processo coronoide ulnar \\
\hline Biceps braquial & Flexiona o antebraço das Araras e auxilia na \\
extensão do ombro & $\begin{array}{c}\text { Porção proximal do } \\
\text { Úmero }\end{array}$ & Porção proximal do Rádio \\
\hline Braquial & Flexiona a articulação do úmero-rádio-ulnar & Úmero & Rádio \\
\hline $\begin{array}{l}\text { Umerotríceps } \\
\text { braquial }\end{array}$ & Estender articulação do cotovelo e da asa & Úmero & Ulna \\
\hline
\end{tabular}

FIGURA 1: Fotomacrografia da região medial do ombro e braço: A. Músculo peitoral torácico, B. Músculo biceps braquial, C. Músculo escapulotríceps braquial, D. Músculo umerotríceps braquial, E. Músculo peitoral propatagial, F. Tendões propatagiais, G. Músculo braquial, H. Úmero. Barra de escala $1 \mathrm{~cm}$.

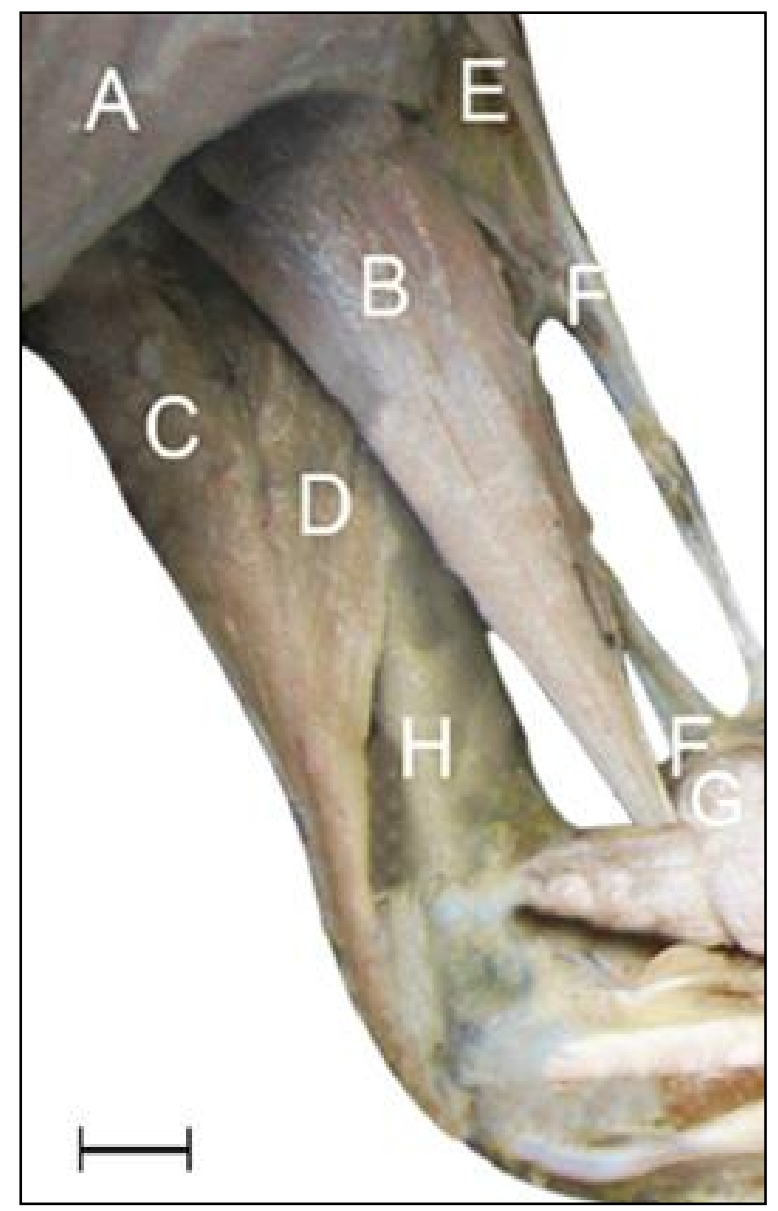


TABELA 2: Músculos da face medial do antebraço das Araras-Canindé.

\begin{tabular}{lcccc}
\hline \multicolumn{1}{c|}{ Músculo } & Funções & Origem & Inserção \\
$\begin{array}{l}\text { Extensor radial do } \\
\text { metacarpo }\end{array}$ & $\begin{array}{c}\text { Extensão do metacarpo e flexiona a } \\
\text { articulação úmero-rádio-ulnar }\end{array}$ & $\begin{array}{c}\text { Epicôndilo lateral do } \\
\text { úmero }\end{array}$ & $\begin{array}{c}\text { Processo extensor do } \\
\text { metacarpo }\end{array}$ \\
\hline $\begin{array}{l}\text { Pronador } \\
\text { superficial }\end{array}$ & Flexionar e abaixar o antebraço & $\begin{array}{c}\text { Epicôndilo medial do } \\
\text { úmero }\end{array}$ & Rádio \\
\hline $\begin{array}{l}\text { Pronador profundo } \\
\begin{array}{l}\text { Extensor longo } \\
\text { digital maior }\end{array}\end{array}$ & Flexionar e abaixar o antebraço & $\begin{array}{c}\text { Epicôndilo medial do } \\
\text { úmero }\end{array}$ & Rádio \\
\hline $\begin{array}{l}\text { Ulnometacarpico } \\
\text { ventral }\end{array}$ & Flexionar e abaixa a face cranial da mão & Face ventral da ulna & Tróclea externa do carpo \\
\hline $\begin{array}{l}\text { Flexor digital } \\
\text { profundo }\end{array}$ & Abaixar e flexionar ventralmente a mão & Face ventral da ulna & Segunda falange \\
\hline $\begin{array}{l}\text { Flexor digital } \\
\text { superficial }\end{array}$ & Abaixar e flexionar ventralmente a mão & $\begin{array}{c}\text { Epicôndilo medial do } \\
\text { úmero }\end{array}$ & Primeira falange \\
\hline $\begin{array}{l}\text { Flexor ulnar do } \\
\text { carpo }\end{array}$ & Flexionar a mão & $\begin{array}{c}\text { Epicôndilo medial do } \\
\text { úmero }\end{array}$ & Carpo-ulnar. \\
\hline
\end{tabular}

FIGURA 2: Fotomacrografia da região medial do antebraço: A. Músculo extensor radial do metacarpo, B. Músculo pronador superficial, C. Músculo pronador profundo, D. Músculo extensor longo digital maior, E. Músculo ulnometacarpico ventral, F. Músculo flexor digital profundo, G. Músculo flexor digital superficial, H. Músculo flexor ulnar do carpo, I. Rádio. Barra de escala $1 \mathrm{~cm}$.

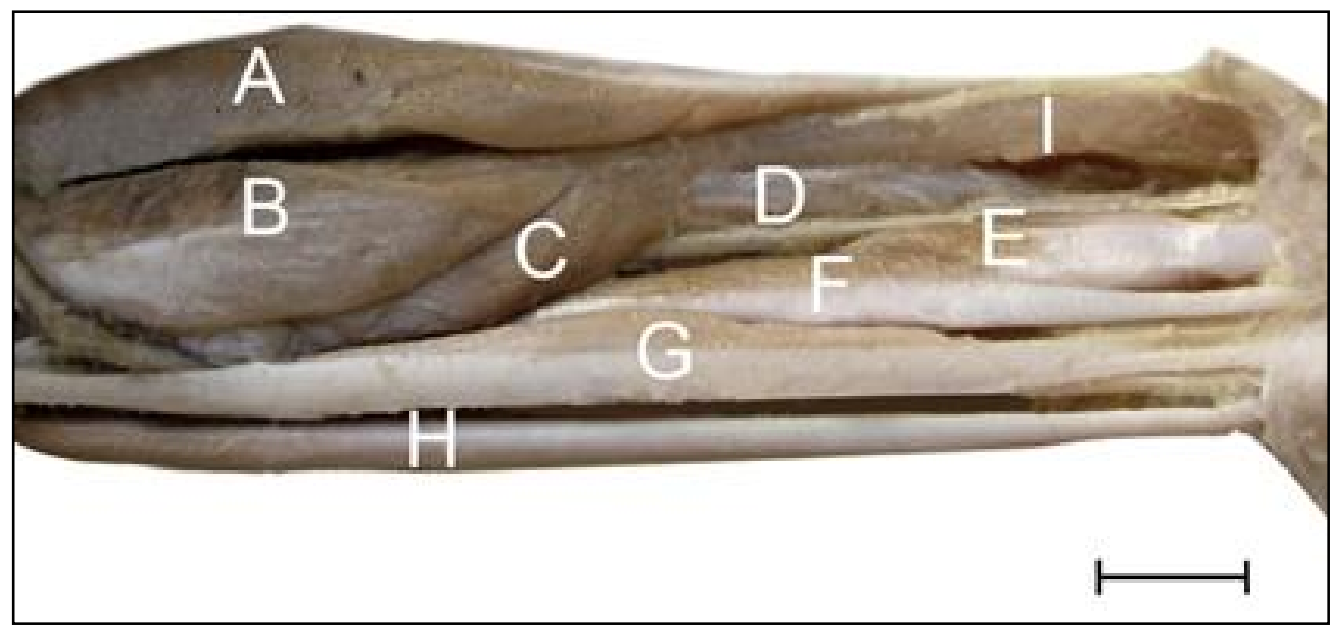

A Tabela 3 apresenta os músculos da face medial da mão (representados na Figura 3), suas respectivas funções, origens e inserções. 
TABELA 3: Músculos da face medial da mão das Araras-Canindé.

\begin{tabular}{lccc}
\multicolumn{1}{c}{ Músculo } & Função & Origem & Inserção \\
\hline Interósseo ventral & Auxilia a extensão do dedo maior & Ossos metacarpianos & Segunda falange \\
\hline $\begin{array}{l}\text { Ulnometacarpico } \\
\text { dorsal }\end{array}$ & $\begin{array}{c}\text { Tração das penas primarias em direção as } \\
\text { penas secundárias }\end{array}$ & $\begin{array}{c}\text { Extremidade distal } \\
\text { da ulna }\end{array}$ & Metacarpo menor \\
\hline Flexor da álula & Flexiona a álula & $\begin{array}{c}\text { Face ventral do } \\
\text { metacarpo }\end{array}$ & $\begin{array}{c}\text { Porção ventral da falange } \\
\text { basal }\end{array}$ \\
\hline $\begin{array}{l}\text { Abdutor digital } \\
\text { maior }\end{array}$ & Estender dedo maior & Metacarpiano maior & Falange do dedo maior \\
\hline Adutor alular & Movimento de adução da álula & Metacarpo & Falange basal \\
\hline $\begin{array}{l}\text { Flexor digital } \\
\text { superficial }\end{array}$ & Flexiona a primeira falange & $\begin{array}{c}\text { Epicôndilo medial do } \\
\text { úmero }\end{array}$ & Primeira e segunda falange \\
\hline $\begin{array}{l}\text { Flexor digital } \\
\text { menor }\end{array}$ & Flexiona a primeira e a segunda falange & Metacarpo & Falange do dedo maior \\
\hline
\end{tabular}

FIGURA 3: Fotomacrografia da região medial da mão: A. Músculo interósseo ventral, B. Músculo ulnometacarpico dorsal, C. Músculo flexor da álula, D. Músculo abdutor digital maior, E. Músculo adutor alular, F. Metacarpo maior, G. Músculo flexor digital superficial, H. Músculo flexor digital superficial, I. Músculo flexor digital menor, J. Álula. Barra de escala $1 \mathrm{~cm}$.

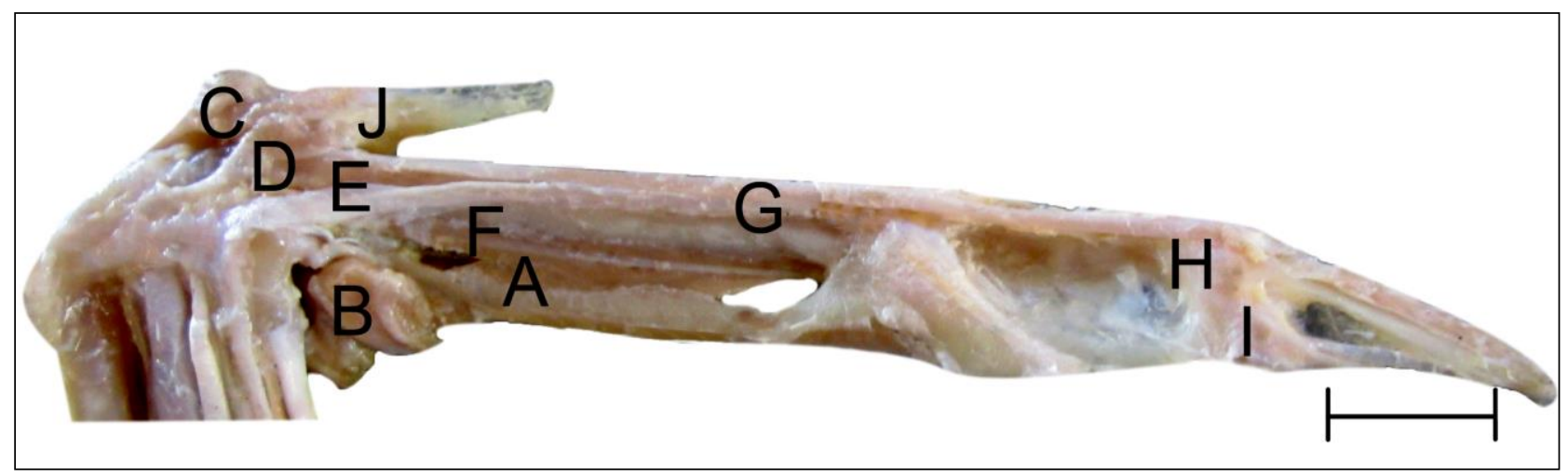

A Tabela 4 apresenta os músculos da face lateral do braço (representados na Figura 4), suas respectivas funções, origens e inserções.
A Tabela 5 apresenta os músculos da face lateral do antebraço (representados na Figura 5), suas respectivas funções, origens e inserções.

TABELA 4: Músculos da face lateral do braço das Araras-Canindé.

\begin{tabular}{|c|c|c|c|}
\hline Músculo & Funções & Origem & Inserção \\
\hline $\begin{array}{l}\text { Escapulotríceps } \\
\text { braquial }\end{array}$ & $\begin{array}{c}\text { Flexionar o ombro e estender a articulaçao } \\
\text { umero-rádio-ulnar }\end{array}$ & Colo da escápula & Processo coronoide da ulna \\
\hline Biceps braquial & $\begin{array}{c}\begin{array}{c}\text { Flexionar o antebraço e auxiliar na extensão } \\
\text { do ombro }\end{array} \\
\end{array}$ & $\begin{array}{l}\text { Ápice do coracoide e } \\
\text { úmero }\end{array}$ & Rádio / Ulna \\
\hline Propatagial & Recobre e protege a articulação do ombro & Osso coracoide & $\begin{array}{l}\text { Tendões propatagiais, } \\
\text { epicôndilo lateral do úmero }\end{array}$ \\
\hline Deltoide maior & Elevação da asa & Escápula & Úmero \\
\hline Deltoide menor & Elevação da asa & Escápula & $\begin{array}{c}\text { Tuberosidade lateral do } \\
\text { úmero }\end{array}$ \\
\hline
\end{tabular}


FIGURA 4: Fotomacrografia da região lateral do braço: A. Músculo propatagial, B. Músculo deltoide maior, C. Músculo escapulotríceps braquial, D. Ligamentos propatagiais E. Músculo bíceps braquial, F. Úmero, G. Nervo radial, H. Músculo Deltoide menor. Barra de escala $1 \mathrm{~cm}$.

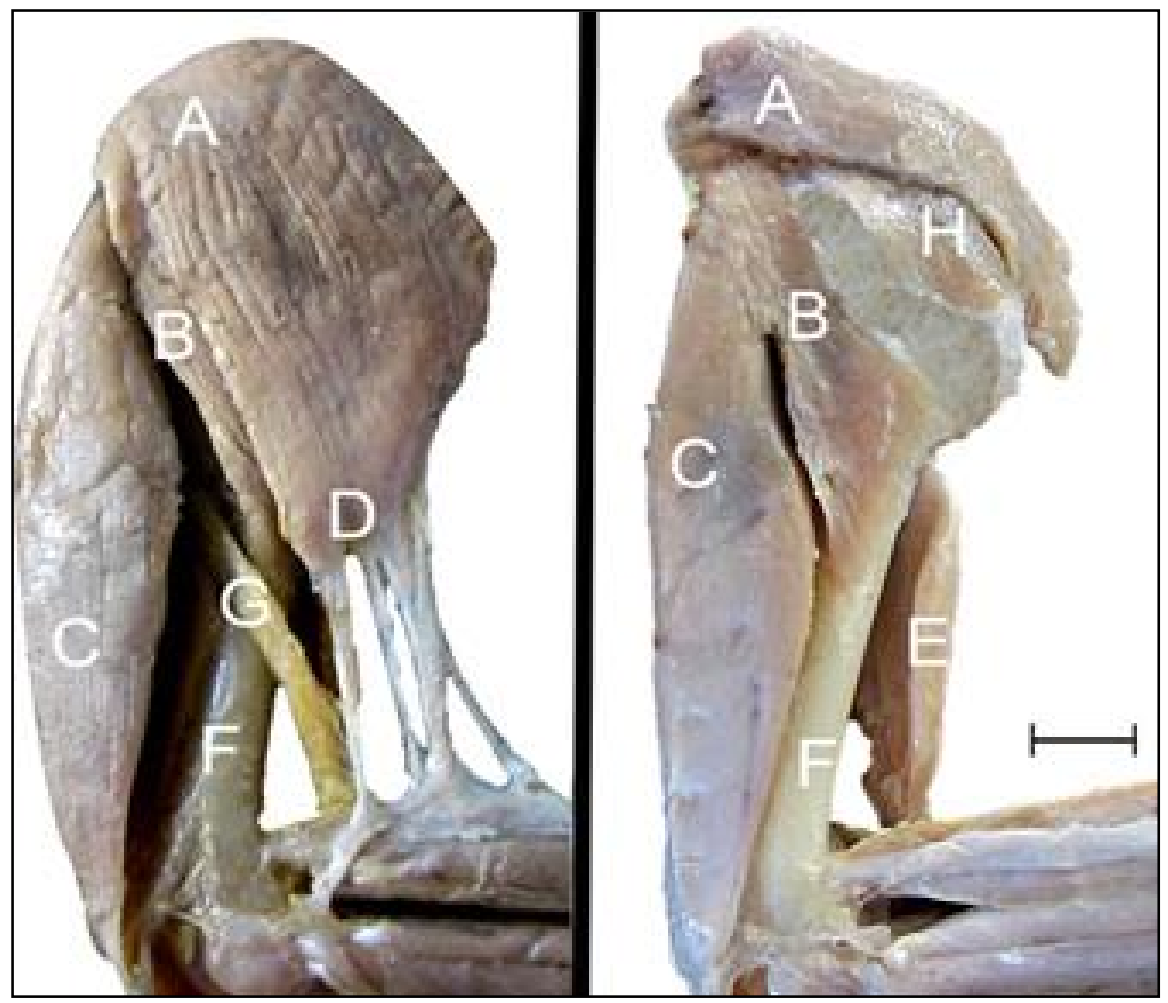

A Tabela 6 apresenta os músculos da face lateral da mão (representados na Figura 6), suas respectivas funções, origens e inserções.

TABELA 5: Músculos da face lateral do antebraço das Araras-Canindé.

\begin{tabular}{lccc}
\hline \multicolumn{1}{c}{ Músculo } & Funções & Origem & Inserção \\
\hline $\begin{array}{l}\text { Extensor radial do } \\
\text { metacarpo }\end{array}$ & $\begin{array}{c}\text { Estender o metacarpo e flexionar a } \\
\text { articulaçao úmero-rádio-ulnar }\end{array}$ & $\begin{array}{c}\text { Epicôndilo lateral do } \\
\text { úmero }\end{array}$ & $\begin{array}{c}\text { Processo extensor do } \\
\text { metacarpo }\end{array}$ \\
\hline Supinador & $\begin{array}{c}\text { Elevar o antebraço, flexionar o antebraço e } \\
\text { supinação da mão }\end{array}$ & $\begin{array}{c}\text { Epicôndilo lateral do } \\
\text { úmero }\end{array}$ & Rádio \\
\hline $\begin{array}{l}\text { Extensor digital } \\
\text { comum }\end{array}$ & $\begin{array}{c}\text { Posicionamento da álula durante o voo, } \\
\text { extensão da mão }\end{array}$ & $\begin{array}{c}\text { Epicôndilo lateral do } \\
\text { úmero }\end{array}$ & Côndilo lateral da ulna \\
\hline $\begin{array}{l}\text { Extensor longo da } \\
\text { álula }\end{array}$ & Extensão da mão & Rádio e Ulna & $\begin{array}{c}\text { Processo extensor do } \\
\text { metacarpo }\end{array}$ \\
\hline $\begin{array}{l}\text { Extensor ulnar do } \\
\text { metacarpo }\end{array}$ & Extensão da mão & $\begin{array}{c}\text { Epicôndilo lateral do } \\
\text { úmero }\end{array}$ & Carpo-metacarpo \\
\hline $\begin{array}{l}\text { Extensor longo } \\
\text { digital comum }\end{array}$ & Extensão da mão & Rádio & Metacarpo \\
\hline
\end{tabular}


FIGURA 5: Fotomacrografia da região lateral do antebraço: A. Músculo extensor radial do metacarpo, B. Músculo supinador, C. Músculo extensor digital comum, D. Músculo extensor longo da álula, E. Músculo extensor longo digital comum, F. Músculo extensor ulnar do metacarpo, G. Ulna. Barra de escala $1 \mathrm{~cm}$.

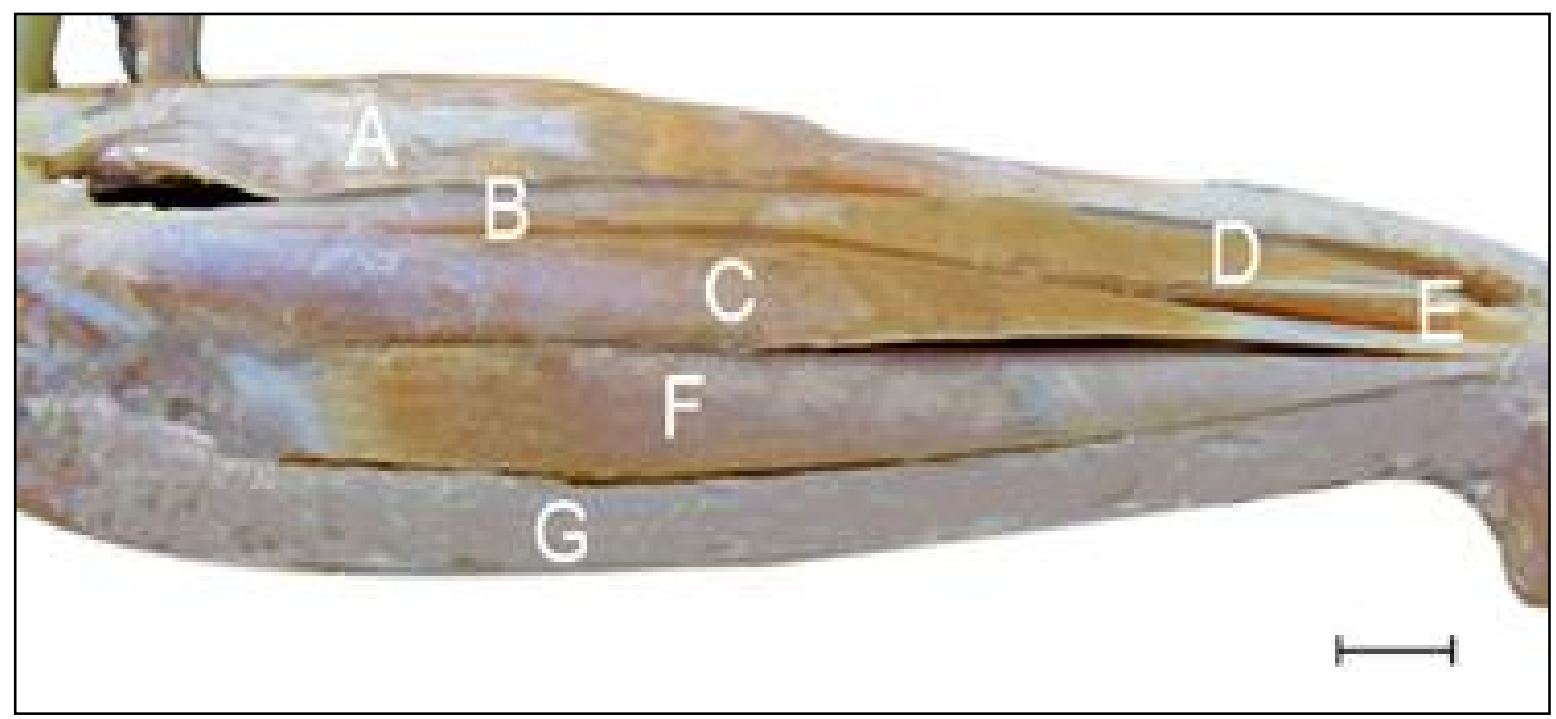

TABELA 6: Músculos da face lateral da mão das Araras-Canindé.

\begin{tabular}{lccc}
\multicolumn{1}{c}{ Músculo } & Funções & Origem & Inserção \\
\hline $\begin{array}{l}\text { Ulnometacarpico } \\
\text { dorsal }\end{array}$ & $\begin{array}{c}\text { Traciona as penas primárias e flexiona a } \\
\text { mão sobre o antebraço }\end{array}$ & Ulna & Metacarpo \\
\hline Interósseo ventral & Auxilia a extensão do dedo maior & Segunda falange \\
\hline Adutor alular & Adução da álula & Metacarpo & Falange basal \\
\hline $\begin{array}{l}\text { Flexor digital menor } \\
\text { Interósseo dorsal }\end{array}$ & Flexiona primeira e segunda falange & Metacarpo & Falange do dedo maior \\
\hline $\begin{array}{l}\text { Extensor breve } \\
\text { alular }\end{array}$ & Auxilia a extensão do dedo maior & Metacarpo & Segunda falange \\
\hline $\begin{array}{l}\text { Abdutor alular } \\
\text { Auriar no movimento abdutor da álula }\end{array}$ & $\begin{array}{c}\text { Processo extensor } \\
\text { metacarpiano }\end{array}$ & Falange basal \\
\hline
\end{tabular}


FIGURA 6: Fotomacrografia da região medial da mão: A. Músculo ulnometacárpico dorsal, B. Músculo interósseo ventral, C. Músculo flexor digital menor, D. Músculo interósseo dorsal, E. Músculo extensor breve alular, F. Álula, G. Músculo adutor alular, H. Músculo abdutor alular. Barra de escala $1 \mathrm{~cm}$.

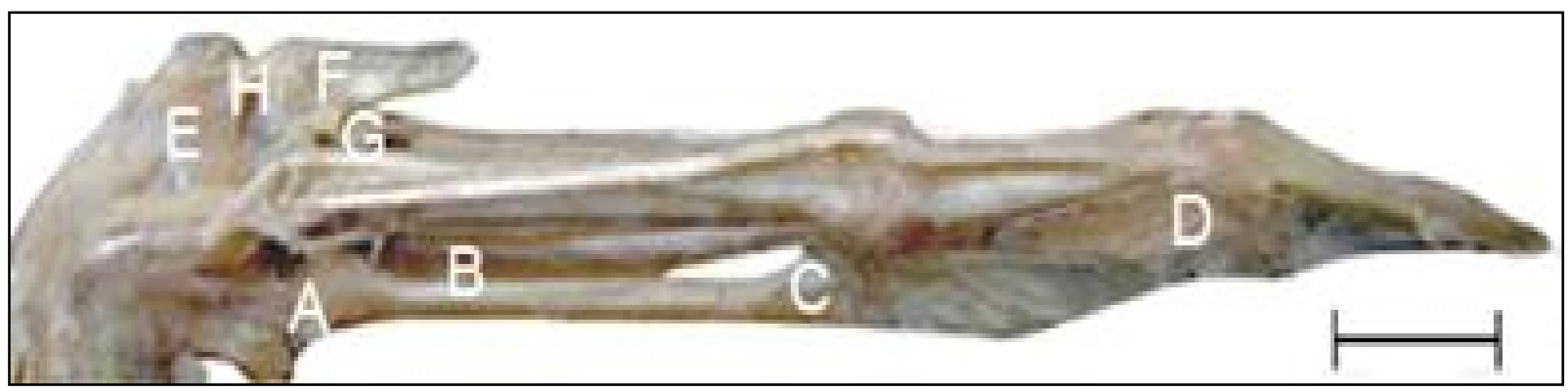

\section{Discussão}

A musculatura das aves está intimamente ligada à estrutura óssea, sendo responsável por $75 \%$ do seu peso, proporcionando locomoção e resistência. Os músculos estão localizados em sua grande maioria na região do peito das aves, local onde estão inseridas as asas, sendo diretamente responsáveis pela movimentação das asas durantes o voo e também pelas ações de decolagem e pouso (BAUMEL, 1981; O’MALLEY, 2005).

Esta concentração da massa muscular proporciona estabilidade para o voo. Os músculos peitorais se estendem a partir do esterno, inserindo-se no úmero. $\mathrm{Na}$ maioria das aves, como Psitaciformes, Falconiformes e Columbiformes os músculos peitorais superficiais formam a massa principal do peito. São os responsáveis pela força descendente do voo, sendo essenciais para as aves se locomoverem. (O'MALLEY, 2005).

Tendo suas asas como principal membro de locomoção, as aves dependem de uma musculatura estruturada similar aos músculos estriados da maioria dos animais, com um grande número de longas fibras ou células alinhadas paralelamente (STURKIE, 2000).

Os movimentos detalhados da asa durante o voo envolvem um grande número de diferentes músculos, tendo como os maiores músculos do voo o peitoral e supra coracoideo. As aves não são capazes de decolar ou aterrissar sem o uso dos músculos do antebraço, mas poderiam sustentar o voo após uma decolagem provida de algum auxílio (STURKIE, 2000).
A musculatura lateral do antebraço mostrou-se constituída por grupos musculares uniformemente dispostos, de acordo com a topografia encontrada por Yasuda (2004), em galinhas (Gallus gallus domesticus), sendo os músculos extensor radial do metacarpo, extensor longo da álula e extensor longo digital maior associados com o rádio, enquanto os músculos extensor digital comum e extensor ulnar do metacarpo foram encontrados em íntimo contato com a ulna.

Medialmente, entre os grupos musculares relacionados com o rádio, estavam os músculos pronador superficial e pronador profundo. Já os músculos: flexor digital profundo, ulnar metacárpico ventral, flexor digital superficial e do carpo estavam relacionados em sua origem com o epicôndilo medial do úmero. Nossos achados condizem topograficamente com o encontrado por Robson et al. (1994), em galinhas (Gallus gallus domesticus), com exceção dos músculos flexor digital superficial e flexor ulnar do carpo, que segundo o autor associam-se com a ulna. Acreditamos que essa diferença faz com que o voo das Araras-Canindé seja facilitado pelo movimento firme e preciso das mãos, enquanto galinhas, apesar de sua inabilidade de voo, podem encontrar mais dificuldades em movimentar a mão por conta encurtamento anatômico relacionado com a origem dos músculos citados. Entretanto estudos biomecânicos prospectivos são necessários para confirmar nossa hipótese.

Hildebrand e Goslow (2006) citam o epicôndilo do lateral do úmero como a origem dos músculos supinador e demais extensores da mão e dos dígitos em codorna 
japonesa (Coturnix coturnix japonica). Porém, observamos que os músculos extensores longo digital comum, longo digital maior e longo digital da álula têm sua origem a partir da porção mais proximal do rádio e o extensor breve alular origina-se a partir do processo extensor metacarpiano.

Ritchie et al. (1994) fizeram uma breve descrição da musculatura da cacatua branca (Cacatua alba), sendo a única comparação encontrada em literatura para a ordem dos Psitaciformes. Todos os músculos citados pelos autores condizem com os encontrados em nosso estudo, porém faltou um detalhamento topográfico mais especifico das origens, inserções e funções dos músculos encontrados pelos autores para poder delinear uma comparação mais significativa.

Schmidt et al. (2003) citam que as injurias que mais acometem a musculatura esqueléticas as aves estão relacionadas a traumas físicos, inflamações nos tendões e neoplasias. As lesões em ligamentos também podem ser ocasionadas por bandagens durante o tratamento de fraturas, podendo ocasionar necrose de pressão em pele e ligamento da área protegida, além da inflamação do local, levando a contraturas e cicatrização do ligamento e assim comprometendo sua função, ao impossibilitar a ave de voar. O conhecimento da anatomia topográfica da musculatura da asa, com o detalhamento específico da origem e inserção dos músculos é de extrema importância para o sucesso de um procedimento cirúrgico, imobilizações e procedimentos gerais, evitando assim possíveis lesões iatrogênicas durante o protocolo de tratamento.

A partir dos resultados, foi possível constatar a existência de pequenas variações anatômicas na origem e inserção de alguns músculos, entretanto, com relação à anatomia topográfica da musculatura, a mesma é semelhante ao descrito na literatura para outras aves como galinhas (Gallus gallus domesticus), codorna japonesa (Coturnix coturnix japônica) e cacatua branca (Cacatua alba). Sentimos o fato de não ser possível comparar com um número maior de aves da ordem Psitaciforme, pois a literatura referente à anatomia topográfica dos psitacídeos é escassa.

\section{Agradecimentos}

Agradecemos à Faculdade de Medicina Veterinária e Zootecnia da Universidade de São Paulo, pela oportunidade do estudo, à Fundação de Amparo à Pesquisa do Estado de São Paulo (FAPESP), pelo apoio à nossa pesquisa, ao CETAS-PB pela doação dos cadáveres e a todos colaboradores envolvidos de forma direta e indireta no nosso trabalho.

\section{Referências}

BAUMEL, J. J. Sistema nervoso das aves. In: GETTY, R. (Ed.). Anatomia dos animais domésticos. Vol. 2. 5. ed. Rio de Janeiro: Interamericana, 1981. p. 1702-1715.

BAUMEL, J. J.; BREAZILE J. E.; EVANS H. E.; KING A. S.; VANDEN-BERGE J. Handbook of avian anatomy: Nomina Anatomica Avium. 2. ed. Vol. 23. Cambridge: Nuttal Ornithological Society, 1993. 779 p.

HILDEBRAND, M.; GOSLOW G. E.; Análise da estrutura dos vertebrados. 2 ed. São Paulo: Atheneu, 2006. 637 p.

McLELLAND, J. A colour atlas of avian anatomy. London: Ed. Wolfe, 1990. $127 \mathrm{p}$.

O'MALLEY, B. Clinical anatomy and physiology of exotic species structure and function of mammals, birds, reptiles and amphibians. New York: Elsevier Saunders, 2005. 269 p.

RITCHIE, B. W.; HARRISON G. J.; HARRISON J. R. Avian medicine: principles and application. 1. ed. Florida: Zoological Education Network, 1994. 1384 p.

ROBSON, L. G.; CRAWLEY, A.; KARA, T.; TICKLE, C. Tissue and cellular patterning of the musculature in chick wings. Development, Cambridge, 120, p. 1265-1276, 1994.

SICK, H. Ornitologia brasileira. Rio de Janeiro: Nova Fronteira, 1997. 862 p.

SCHMIDT, R. E.; PHALEN, D. N; REAVILL, D. R Pathology of pet and aviary birds. Ames: Iowa State Press, 2003. 250 p.

STURKIE, P. D.; AZEVEDO, R. B.; MACEDO, L. S. M.; QUITIAQUEZ, J. J.; SILVEIRA, L. F.; WHITTOW, G. C. Sturkie's avian physiology. 5. ed. California: Academic Press, 2000. 685 p.

YASUDA, M. The anatomical atlas of Gallus. 1. ed. Tokio: University of Tokyo Press, 2004. 464 p. 